\title{
A friendly-Biological Reactor Simulator (BioReSIM) for studying biologial processes in wastewater treatment processes
}

\author{
Raúl Molina Gil \\ Department of Chemical, Energy and Environmental Technology. \\ King Juan Carlos University. \\ raul.molina@urjc.es \\ María Isabel Pariente Castillo \\ Department of Chemical, Energy and Environmental Technology. \\ King Juan Carlos University. \\ isabel.pariente@urjc.es \\ Ioanna Vasiliadou \\ Department of Chemical, Energy and Environmental Technology. \\ King Juan Carlos University. \\ vasiliadou.ioanna@gmail.com
}

\author{
Iván Rodríguez Hernández \\ Department of Chemical, Energy and Environmental Technology. \\ King Juan Carlos University. \\ ivan.rodriguez.hernandez@urjc.es

\section{Fernando Martínez Castillejo} \\ Department of Chemical, Energy and Environmental Technology. \\ King Juan Carlos University. \\ fernando.castillejo@urjc.es \\ Juan Antonio Melero Hernández \\ Department of Chemical, Energy and Environmental Technology. \\ King Juan Carlos University. \\ fernando.castillejo@urjc.es
}

|Presented: 14/07/2014 | Accepted: 29/10/2014 |Published: 23/12/2014

\begin{abstract}
The performance of biological reactors longer times than those usually devoted to regular laboratory demonstrations. Biological wastewater treatments are inherently dynamic systems and any change in the operation conditions would take several weeks for stabilization. In order to overcome this lack, computer simulations are useful tools to describe and predict the overall performance of bioreactors under different operation conditions. In this work, we present BioReSIM, a MATLAB code in a friendly and graphic user interface for the simulation of sequencing batch reactors (SBR) and rotating biological contactors (RBC) as biological systems of suspended and attached biomass for wastewater treatment, respectively.
\end{abstract}

Keywords: Mathematical modeling, Wastewater treatment, Sequencing Batch Reactor, Rotating Biological Contactors

\section{Resumen}

El estudio de sistemas biológicos de tratamiento de aguas está limitado a nivel de laboratorio, debido fundamentalmente a los grandes periodos de estabilización necesarios ante cualquier perturbación o cambio de operación del reactor. Los modelos y simulaciones matemáticas pasan a ser fundamentales para el estudio de este tipo de sistemas. En este trabajo, presentamos BioReSIM, un simulador para reactores secuenciales tipo SBR y biodiscos rotatorios tipo RBC de tratamiento de aguas residuales, ejemplo de sistemas de biomasa suspendida y soportada. BioReSIM está programado en MATLAB y se controla a través de una interface gráfica de fácil manejo.

Palabras clave: Modelado Matemático, tratamiento de aguas residuales, reactores secuenciales tipo SBR, biodiscos rotatorios tipo RBC

\section{Resum}

L'estudi de sistemes biològics de tractament d'aigües està limitat a nivell de laboratori, a causa fonamentalment als grans períodes d'estabilització necessaris davant qualsevol pertorbació o canvi d'operació del reactor. Els models i simulacions matemàtiques passen a ser fonamentals per a l'estudi d'aquest tipus de sistemes. En aquest treball, presentem BioReSIM, un simulador per a reactors seqüencials tipus SBR i biodiscs rotatoris tipus RBC de tractament d'aigües residuals, exemple de sistemes de biomassa suspesa i suportada. BioReSIM està programat en MATLAB i es controla a través d'una interfície gràfica de fàcil maneig.

Paraules clau: Modelatge Matemàtic, tractament d'aigües residuals, reactors seqüencials tipus SBR, biodiscs rotatoris tipus RBC 


\section{Introduction}

It is well known that the study of biological reactors for wastewater treatment can be very time consuming, since any changes in operational conditions would require long times until the new steady-state conditions are achieved. For that reason, computer simulations can be used as alternative to study the behavior of the system in order to predict the performance of biological processes under different circumstances (Lant y Emmett 2001).

One of the main problems in the use of simulators and mathematical models is the background in numerical methods and computer programming that are usually necessary for the development of the simulations, especially for time dependant systems. That is the case of low level programming tools $(C++$, FORTRAN,...) and general mathematical tools (Matlab, Octave, Mathematica,...) which allow a considerable flexibility to create any model that was needed to describe the performance of a biological system, although they are restricted to people (researchers, students and tutors) familiar and comfortable with programming. This can be solved using specific simulation tools for environmental studies, such as AQUASIM, SIMBA or $B I O W I N$, that provide a complete set of numerical methods for the solution of the mathematical part of the models. However, these programs could require long learning processes due to the complexity and variety of data necessary for a proper formulation of the biochemical processes and specification of the bioreactors. However, this is far from the real objective of a simulator as a tool to study the behavior of a biological reactor and the influence of operation parameters in the overall performance of the system (Morgenroth et al. 2002).

In this work, we present a Biological Reactor SIMulator (BioReSIM) designed in the Chemical and Environmental Engineering Group in Universidad Rey Juan Carlos as hybrid tool between both approaches. This tool allows freely specification of models in two different kinds of biological systems: i) sequencing batch reactors (SBR) and ii) rotating biological contactors (RBC). Both of them are presented in a friendly graphic user interface programmed in $M A T L A B$. The model formulation is based on the genera structure implemented by the International Association on Water Pollution Research and Control task group on mathematical modeling for design and operation of biological wastewater treatment (Henze et al. 1986). Thus, conventional models for biological systems such as ASM1, ASM2d and other related bio-kinetic models can be easily formulated, modified and tested (Henze et al. 2000). The SBR module allows the simulation of all the stages of the reactor (multiple aerobic and anaerobic fill and reaction stages, settle, discharge and idle), whereas the RBC module considers the biofilm as a one-phase effective solid media where diffusion and reaction takes place, in contact with an external bulk liquid phase.

The BioReSIM includes all the tools for the numerical resolution of the set of nonlinear ordinary differential and partial derive equations describing the systems and making not necessary previous programming knowledgement. It must be also pointed out that BioReSIM is able to not only simulate but also estimation of kinetic parameters and sensitivity analysis, as a complete tool for students and researchers in the field of modelling and simulating environmental processes related to biological treatments in wastewater treatments.
2. Fundamentals and mathematical description of a sequencing batch reactor (SBR)

A SBR is a special form of activated sludge treatment in which the entire process (reaction, settle, empty and idle stages to obtain a clarified effluent and sludge purge) takes place in the same tank (Poltack 2005; Fernández et al. 2013). The treatment of the wastewater is in batch mode and each batch or cycle is sequenced by different consecutive stages (Figure 1):

1. Fill stage: The wastewater is fed to the tank and mixed with the remaining sludge of the tank, under aeration or not aeration conditions.

2. Reaction stage: The reactions of microbial growth and substrate consumption take place under aerated or non aerated conditions. Stages 1 and 2 can be sequent repeated depending on the system. Actually, this is one of the main advantages of SBR systems, since it is possible controlling the organic loading in the tank by a sequence of filling/reaction stages. Moreover, the reactor can be operated alternating aerobic and anoxic stages in the reaction period for nitrogen reduction by nitrification and denitrification.

3. Settle stage: Mixing and aeration (if any) are stopped, allowing the suspended solids of the sludge to be settled to the bottom of the tank.

4. Discharge stage: The treated and clarified effluent is discharged from the reactor.

5. Idle stage: Mixing and, if necessary, aeration, starts again in order to stabilize the sludge before the following cycle.

If a purge of sludge is necessary due to the excess of biomass growth, this can be done in any stage, although is commonly performed at the end of the final reaction stage or after the settle stage. Finally, the behavior of each cycle at steady-state is identical in terms of concentration of components and value of significant parameters.

\subsection{SBR mass balances in the BioReSIM}

As it has been previously mentioned, the wastewater is filled and the treated effluent is discharged from the SBR tank along different stages, being necessary the study of the SBR as a variable volume reactor.

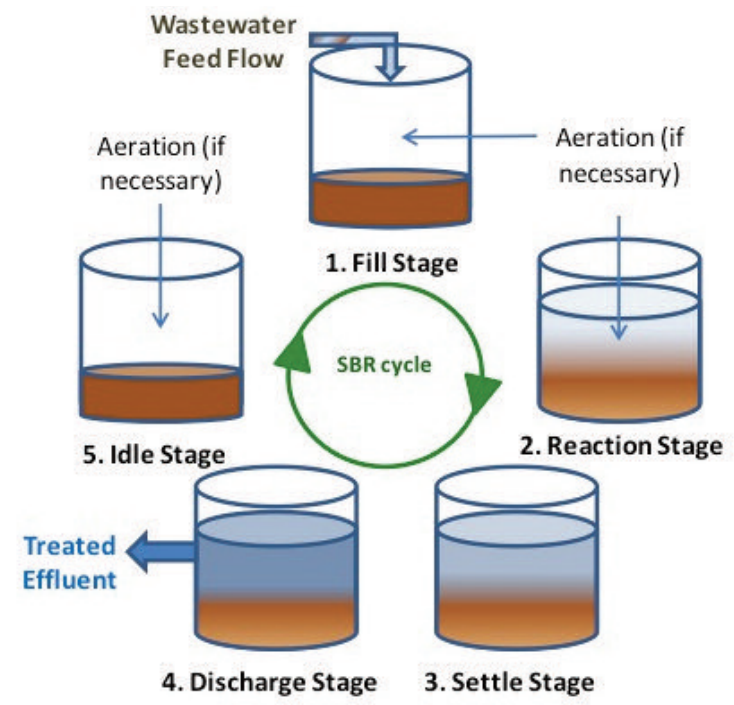

Figure 1. Typical SBR process 
During the fill stage the volume of the tank is gradually increased, the dissolved components suffer a partial dilution or concentration, depending on the wastewater composition, and the solid components are diluted according to the difference between the initial volume and the volume at the end of the stage. Taking all of this into account, mass balances for dissolved and particulate components, as well as the variation of volume in the reactor during the stage can be mathematically described by equations 1 and 2 , respectively. In these equations, $C_{i}$ is the concentration of component $i$. In case of biomass or particulate component, $C$ is usually substituted by $X$; $Q$ is the volumetric feedflow; $V$ is the current filled volume of the reactor; $C_{E} i$ is the concentration of component $i$ in the feed flow; $\overline{C_{i}}(t=0)$ is the oncentration of component $i$ in the reactor at the beginning of the cycle. On the other hand, if the fill stage occurs under aeration conditions, the mass balance for the oxygen follows equation 3 , where $k_{2}$ and $\mathrm{O}_{2}$ saturation are the oxygen mass transfer constant and the saturation oxygen in water (dependant of temperature), respectively. In thses equation, terms $r_{\mathrm{Ci}}$ and $r_{\mathrm{O}_{2}}$ are related to the variation rate for each component $i$ or the oxygen, usually function of different $C_{i}$, oxygen concentration $\mathrm{O}_{2}(t)$ and suspended biomass.

$$
\begin{aligned}
\frac{d C_{i}}{d t} & =\frac{Q}{V}\left(C_{E_{-} \mathrm{i}}-C_{i(t=0)}\right)+r_{C i} \\
\frac{d V}{d t} & =Q \\
\frac{d O_{2}}{d t} & =k_{O 2} \cdot\left(O_{2_{-} \text {saturation }}-O_{2}(t)\right)+r_{O 2}
\end{aligned}
$$

In the reaction stage, there is not feed flow and the liquid volume of the bioreactor is constant. Thus, mass balances for dissolved and particulate components and oxygen (if aeration) follow equations 4 and 5 , which are the previous equations when $Q=O$.

$$
\begin{aligned}
\frac{d C_{i}}{d t} & =r_{C i} \\
\frac{d O_{2}}{d t} & =k_{O 2} \cdot\left(O_{2 \_ \text {saturation }}-O_{2}(t)\right)+r_{O}
\end{aligned}
$$

Assuming that biological conversion takes place only during the fill and reaction stages, the concentration of dissolved components does not change during settling, emptying and idle phases, except fot thedissolved oxygen if the idle is under aeration conditions, which follows equation 5 .

Finally, the concentration and mass of particulate components changes due to a combination of the efficiency of the sedimentation and withdrawing of the clarified effluent from the reactor tank. If the excess of sludge is purged at the end of the reaction step and the settling is complete with no discharge of suspended solids in the effluent stream, the concentration of any particulate component after the purge and at the end of each cycle can be calculated from the mass balance equations 6 and 7, respectively. Additionally, the volume of purge appearing in equation 6 is calculated according to equation 8 .

$$
\begin{aligned}
& X_{\text {affer_purge }}=X_{\text {before_purge }} \cdot\left(1-\frac{V_{\text {purge }}}{V_{T}}\right) \\
& X_{\text {end_cycle }}=X_{\text {affer_purge }}\left(\frac{V_{T}}{V_{T}-V_{\text {discharged effuent }}}\right) \\
& V_{\text {purge }}=Q_{\text {purge }} \cdot t_{T}=\left(\frac{X_{\text {befor_purge }} \cdot V_{T}}{\theta \cdot X_{\text {befor_purge }}}\right) \cdot t_{T}
\end{aligned}
$$

In these equations $X_{\text {before }}$ purge and $X_{\text {after }}$ purge are the concentration of the particulate component before and after the purge, respectively; $V_{\text {purge }}$ is the volume drawn from the reactor during purge; $V_{T}$ is the volume of the totally filled reactor; $V_{\text {discharged }}$ effluent $i s$ the volume of clarified water discharged from the reactor; $Q_{\text {purge }}$ is the volumetric purge flow and $t_{T}$ and $\theta$ are the total time for a complete cycle (including all the stages) and the sludge retention time selected to maintain cyclic steady-state operation conditions, respectively.

\section{Fundamentals and mathematical description of a RBC system}

The rotating biological contactor (RBC) is a fixed film biological secondary treatment device in which a series of closely spaced discs are anchored to a shaft which is supported above the surface of the wastewater and is continually rotating. Usually, about $40 \%$ of the total surface area of the disks is always submerged in the wastewater. Over the disks surfaces grow a biofilm with a variable thickness as result of attachment and detachment processes which are dependent on the operation condition of the bioreactor. The microorganisms attached to the disks are able to absorb nutrients and organic matter from the wastewater for aerobic decomposition while they are submerged. The continuous rotation of the disks makes them to be out of water for certain time, which enable the transfer of oxygen from the air to the biological layer. The continuous movement also produces the detachment of biofilm, which will be responsible of suspended solids in the outlet effluent (Pathwardan 2003; Pariente et al. 2013). Typically, a single RBC is not sufficient to achieve the desired level of treatment, so several RBC units in series are used as shown in Figure 2. Each individual $\mathrm{RBC}$ is called a stage and different conditions of rotating speed and submerged disk area can be established in each stage if necessary.

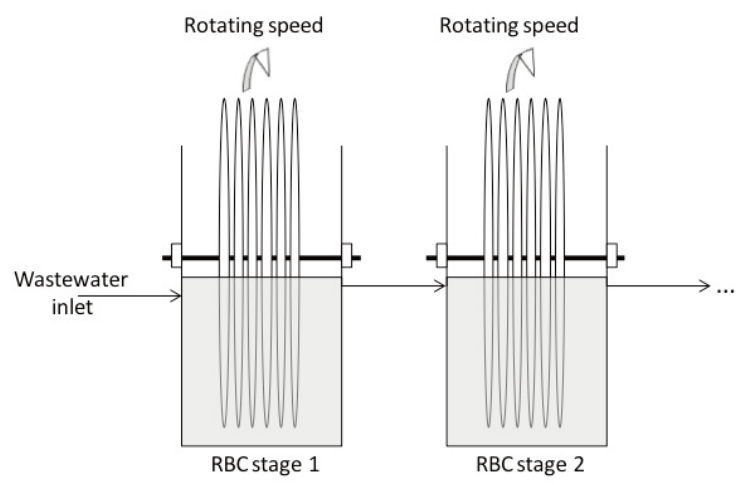

Figure 2. Scheme of two-stage RBC system 


\subsection{RBC mass balances in the BioReSIM}

In BioReSIM, each RBC stage consists of a pseudo-homogeneous model with two zones: i) the bulk aqueous mixture considered as the total volume reactor and modeled as a perfect mixed reactor, and ii) the biofilm matrix considered as the effective solid phase where diffusion and reactions take place. Both zones are in contact and the substrates are transferred to the biofilm through the interphase. In the biofilm, one dimension spatial gradients perpendicular to the disc-plate are calculated for microbial species and substrates. BioReSIM calculates the development over time of microbial (particulate) species, substrates and biofilm thickness. The main assumptions for the formulation of the model are summarized following:

- The bulk liquid volume remains constant, while the biofilm volume increases.

- The biofilm thickness increases, while the biomass concentration inside the biofilm remains constant.

- The dissolved and suspended components are uniformly distributed in the liquid phase of RBCs and they diffuse from the liquid into the biofilm.

- The dissolved nutrients and components are degraded in the liquid phase by suspended biomass and inside the biofilm by immobilized biomass.

- The biofilm density remains constant in time and space.

- The biofilm growth is only modeled in one-dimension, perpendicularly to the disk.

- The biofilm thickness is meshed by finite differences in 10 parts for calculation purposes. The size of each part is variable with time as biofilm thickness increases or decreases due to the biochemical processes.

The mass balances for dissolved components and oxygen in the bulk reactor are described in equations 9 and 10, respectively.

(9) $V \frac{d C_{B_{-} i}}{d t}=Q \cdot\left(C_{E_{-} i}-C_{B_{-} i}\right)-A \cdot D_{i} \cdot\left(\frac{\partial C_{B_{-} i}}{\partial y}\right)_{y=L}-V \cdot r_{C_{B_{-} i}}$

(10) $V \frac{d O_{B}}{d t}=Q \cdot\left(O_{E}-O_{B}\right)-A \cdot D_{O 2} \cdot\left(\frac{\partial O_{B}}{\partial y}\right)_{y=L}-V \cdot r_{O_{B}}+V \cdot f_{\text {AERATION }}$

In these equations, $C_{B} i$ and $C_{E} i$ are the concentration of component $i$ in the bulk reactor stage and in the feed flow, respectively; $A$ is the total wetted surface area of biodiscs in the stage; $D_{i}$ and $D_{\mathrm{O}_{2}}$ are the diffusion coefficients for component $i$ and oxygen, respectively; $L$ is the biofilm thickness (variable with time); $O_{E}$ and $O_{B}$ are the concentration of oxygen in the feed flow and the bulk reactor stage, respectively; $f_{A E R A T I O N}$ is an external aeration function and $r_{C B} i$ and $r_{O B}$ are the variation rate of dissolved components and oxygen in the bulk reactor.

The rotation of the disk promotes the oxygen transfer from the air to the external face of biological layer, which is in contact with the bulk solution. Thus, this aeration effect is included in the term $f_{A E R A T I O N}$ in equation 10. BioReSIM uses a perfect mixed reactor for the bulk liquid phase and a boundary condition that equals the concentration of all dissolved components (oxygen included) in the external face of the solid biofilm with the bulk liquid phase (see equation 17).
The mass balance for particulate components in the bulk reactor is shown in equation 11, where the $U_{R E S}$ term is the resultant attachment/detachment processes rate. This term (equation 12) compute the change rate in the biofilm thickness due to attachment of particulate compounds from the bulk reactor to the biodisc surface or the contrary process, so-called detachment.

$$
\begin{array}{r}
\frac{d X_{B_{-} i}}{d t}=Q \cdot\left(X_{E_{-} i}-X_{B_{-} i}\right)+V \cdot r_{X B_{-} i}-U_{R E S} \cdot A \cdot X_{\text {Biofim }} \\
U_{R E S}=U_{\text {Attachment }}-U_{\text {Detachment }}
\end{array}
$$

$X_{B \_} i$ and $X_{E} i$ are the concentration of biomass in the bulk solution and the feed flow; $r_{X B} i$ is the variation rate of each type of biomass (i) in the bulk reactor; $U_{\text {Attachment }}$ and $U_{\text {Detachment }}$ are the attachment and detachment rate of suspended biomass, computed as increase or decrease of biofilm thickness per time, respectively.

The mass balance for dissolved components (including oxygen) in the biofilm follows equation 13, whereas the biofilm growth can be mathematically described by equation 14. In these equations, $C_{i}$ is the concentration of component $I$ in the biofilm, $r_{C i}$ is the variation rate for each component in the biofilm and $\rho_{\text {Biofilm }}$ is the biofilm density.

It should be pointed out that this equation is a typical example of the moving boundary Stefan-like problem. The term is the average biomass growth rate in the biofilm and can be calculated according to equation 15 .

$$
\begin{array}{r}
\frac{\partial C_{i}}{\partial t}=D_{i} \frac{\partial^{2} C_{i}}{\partial y^{2}}+r_{C i} \\
\rho_{\text {biofilm }} \frac{d L}{d t}=L \cdot r_{x i}+U_{R E S} \cdot \rho_{\text {biofilm }} \\
\overline{r_{x i}}=\frac{1}{L} \int_{0}^{L} r_{x i} d y \cong \sum_{n=0}^{10} r_{x i}^{n} \cdot \Delta y^{n} \rightarrow \text { where } \sum_{n=0}^{10} \Delta y^{n}=L
\end{array}
$$

The boundary conditions necessary for a complete definition of the problem can be enunciated as follows:

- A negligible diffusion of components from the biofilm to the material of the disc surface (equation 16).

- The concentration of dissolved components in the external surface of the biofilm is the same that the concentration in the bulk liquid phase of the reactor (equation 17), and also the concentration of the outlet effluent of the reactor as perfect mixed model is considered for the bulk liquid phase.

$$
\begin{array}{r}
\left.y=0 \rightarrow \frac{\partial C_{i}}{\partial y}\right]_{y=0}=0 \\
y=L \rightarrow C_{i}=C_{B_{-} i} \therefore X_{i}=X_{B_{-} i}
\end{array}
$$




\section{Mathematical modelling of biochemial processes in BioReSIM}

The variation rate of each component $\left(r_{C j}\right)$ is a set of equations that describes all the dynamic biochemical processes and the interactions between the components of the system. The method used to describe the set of kinetic rates is popular for technical biochemical systems according to the report of the IAWQ task group on mathematical modeling for design and operation of biological wastewater treatment. This method is commonly used in commercial software for modeling wastewater treatment plants (Henze et al. 2000). Usually, a biological or chemical process transforms several substances in fixed stoichiometric proportions. Thus, the transformation rates can be defined by a mathematical equation that describes the process and a set of stoichiometric parameters that take into account the contribution of the process to the temporal change of the concentration of each component (equation 18).

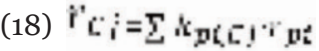

where $r_{C j}$ is the total transformation rate for component $C_{j}$ and is equivalent to $r_{C i}, r_{O 2}, r_{C B}, r_{O B}$ and $r_{X i}$ in equation 1-17, $k_{p i}, c_{j}$ is the stoichiometric coefficient for component $C_{j}$ respect to process $p_{i}$ and $r_{p i}$ is the rate of the process $p_{i}$

The formulation of each biochemical processes following this method allows a clear presentation of the overall biological process using a matrix as that shown in Table 3 . Nonzero values of $k_{i, j}$ means components influenced by process $p_{i}$, whereas zero values of $k_{i, j}$ are characteristic of components non-influenced by that process. Additionally, the sign of the coefficient means consumption (-) or production (+) of the component. Summarizing, a proposed model should compromise the following steps (Table 1):

1. Identification of components (dissolved and particulate substances).

2. Proposal of processes occurring in the reactor.

3. Mathematical description of each process.

4. Correlation of the mathematical equation for each process with the components described in step 1 through appropriate stoichiometric coefficients.

\begin{tabular}{|c|c|c|c|c|c|}
\hline \multirow{2}{*}{ Processes } & \multicolumn{4}{|c|}{ Components } & \multirow{2}{*}{ Equation rate } \\
\hline & $C_{1}$ & $C_{2}$ & $C_{3}$ & $C_{\ldots}$ & \\
\hline$p_{1}$ & $k_{1,1}$ & $k_{1,2}$ & $k_{1,3}$ & $k_{1, \ldots}$ & $r_{p 1}$ \\
\hline$p_{2}$ & $K_{2,1}$ & $k_{2,2}$ & $k_{2,3}$ & $k_{2, \ldots}$ & $r_{p 2}$ \\
\hline $\boldsymbol{p}_{3}$ & $k_{3,1}$ & $k_{3,2}$ & $k_{3,3}$ & $k_{3, \ldots}$ & $r_{p 3}$ \\
\hline$p .$. & $k_{\ldots, 1}$ & $k_{\ldots, 2}$ & $k_{\ldots, 3}$ & $k_{\ldots, \ldots}$ & $r_{p \ldots}$ \\
\hline \multicolumn{6}{|c|}{ 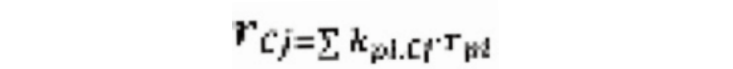 } \\
\hline
\end{tabular}

Table 1. Matrix representation of a process model

\section{The BioReSIM code}

The BioReSIM allows to make models for the description of the performance of SBR and RBC bioreactors as well as to study the influence of the operating variables of these biological systems. According to the previous description, a model consists of a system of ordinary differential equations (ODE) and partial differential equations (PDE) which describes the behavior of a given set of variables with time. The $\mathrm{PDE}$ in the RBC system is transformed in a set of additional ODE dividing the biofilm thickness in 10 equals segments by the finite differences method. Figure 3 shows a graphic representation of all the parts of a simulation, those that can be defined by the user and those parts already implemented in the software. The equations describing the different biochemical processes that can be freely determined by the user and the formulation of the equations following closely the notation described in Table 3 . The definition of the processes can be done using two different variables:

1. Components: They represent substances of influence in the different biochemical processes that are defined in the model.

2. Parameters: Set of kinetic parameters and stoichiometric coefficients that establish the relationships between the components and the different_biochemical processes.

The main screen of BioReSIM is shown in Figure 4. It is divided in 3 panels:

1. The Kinetic model panel, used for the kinetic model generation. The processes, components and parameters of the model will be defined here.

2. The Control panel, with different options: save and load models, open pdf documents with literature of interest, help and calculate function.

3. The Reactor system panel with the reactor systems currently available for simulation and evaluation.

\subsection{The Kinetic model panel}

This panel contains three boxes for components, parameter and processes definition. The components' box shows the substances already defined in the model by the button Add (Figure 4). The Add button allows the definition of a new component (Figure 5a), units for concentration (all the components and parameters should be introduced in homogenous units, taking into account that time should be in days and volume in liters), initial concentration of the component in the reactor $(\mathrm{t}=\mathrm{O})$, concentration in the feed flow and the characterization as dissolved or particulate compound. $\mathrm{Ob}-$

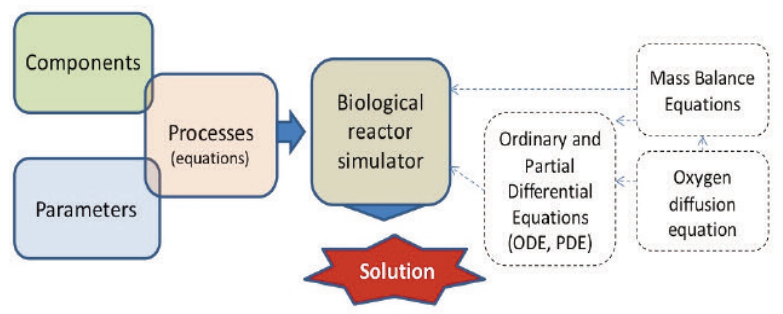

Figure 3. Schematic description of the biological process simulation. Straight line boxes are the three conceptual parts that have be defined by the user. Dash line boxes include the different mathematical equations needed by the BioReSIM application. 


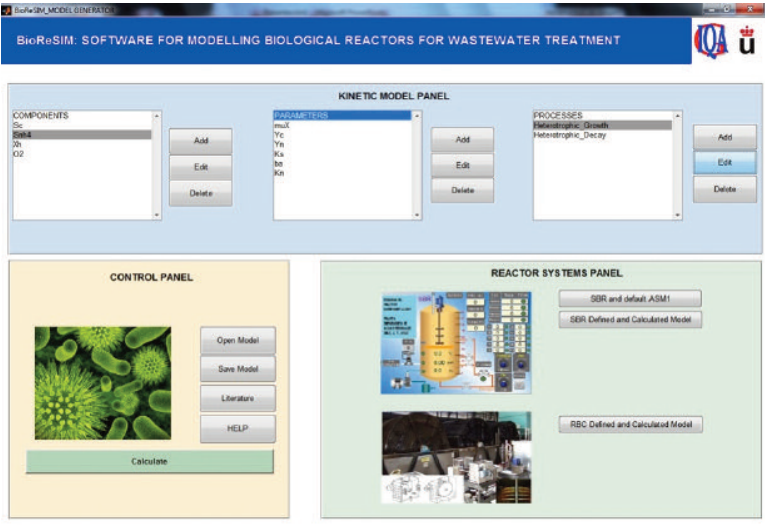

Figure 4. Main screen of BioReSIM: Model definition and file handling buttons

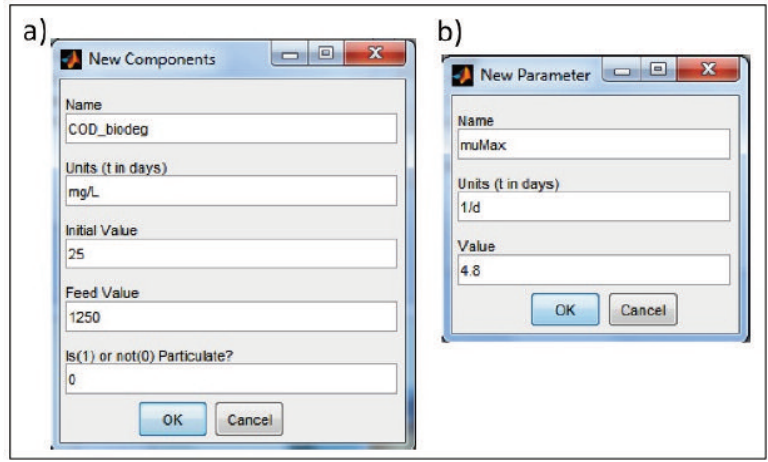

Figure 5. a) New component and b) new parameter boxes

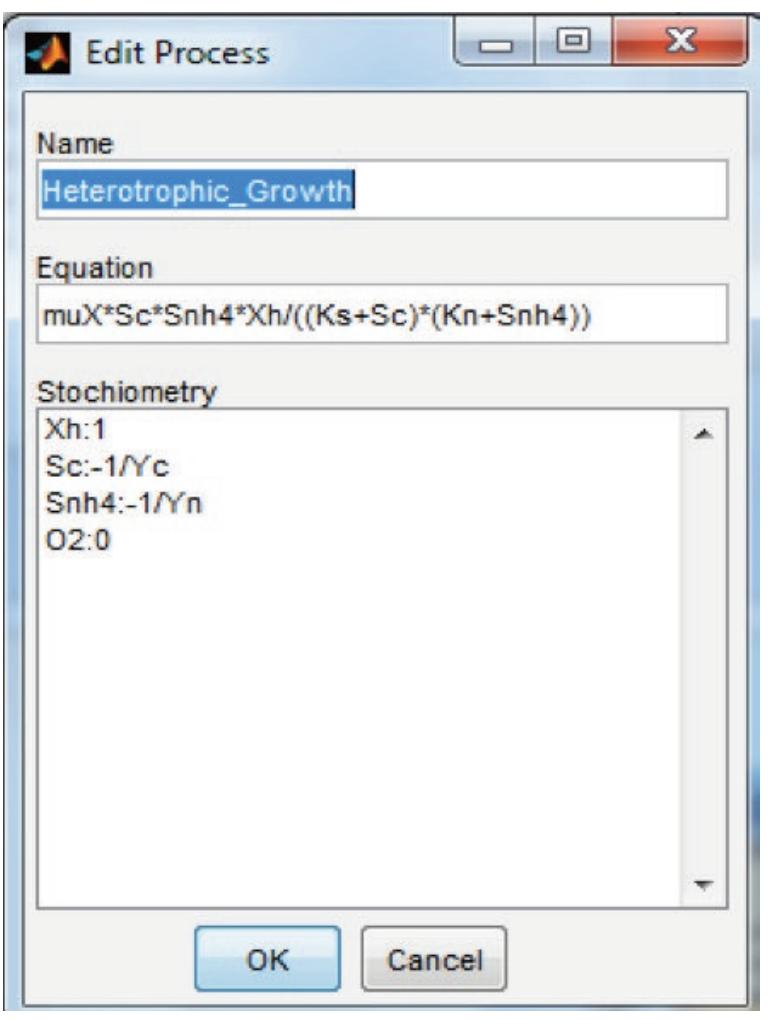

Figure 6. Dialog box for editing a process (heterotroph microbial growth) affecting components $\mathrm{X}_{\mathrm{h}}, \mathrm{S}_{\mathrm{C}}, \mathrm{S}_{\mathrm{nh}}, \mathrm{O}_{2}$, with kinetic parameters muX, $\mathrm{K}_{\mathrm{S}}$ and $\mathrm{K}_{\mathrm{n}}$ and stoichimetric coefficients defined as functions of $Y_{C}$ and $Y_{n}$. Components and parameters are previously defined. viously, each component can be edited or deleted once defined. The only restriction is that the oxygen should be always the last component defined in the components' box.

The parameters' box shows the kinetic parameters, stoichiometric coefficients and all the variables that are not component concentrations included in the model (Figure $5 \mathrm{~b}$ ). The same considerations about the units previously mentioned should be taking into account for the parameter definition.

Figure 6 shows the dialog box used for defining or editing a biochemical process of the model. The Name is a sequence of letters and digits identifying the process. The Equation contains the mathematical description of the process with all the components and kinetic parameters involved. In the Stoichiometry, for each component affected by the process, a stoichiometric coefficient is defined as an algebraic expression, including digits and parameters previously defined in the parameter's box. Obviously, the components before the colon should be previously added in the components' box.

\subsection{The Control panel}

The main function of the control panel is the Calculate button, that allows obtaining a complete mathematical equation for the variation rate of each component defined in the model (Figure 7). Additionally, different button options for saving the model in EXCEL format (Save Model button) and open after to be saved (Open Model button) are included. Finally, the program includes some tips for the model definition (HELP button) as well as a direct access to useful literature in PDF format (Literature button), accessible depending on the institution licenses (university, research centers, etc.). The literature should be independently included after installation of the program.

\subsection{The Reactor sistems panel}

After the previous steps, the model is completed and ready to be used in the biological reactors available in this panel. Currently, the mass balances of two biological reactors (SBR and RBC) have been included in BioReSIM, so only these two of biological processes can be simulated. In the case of the SBR, different models based on the Activated Sludge Model $\mathrm{N}^{0} 1$ (ASM1) by the International Association on Water Quality (IAWQ) are pre-defined and accessible by the SBR and default ASM1 button (Henze et al. 2000; Schulthess y Gujer 1996). The methodology for the simula-

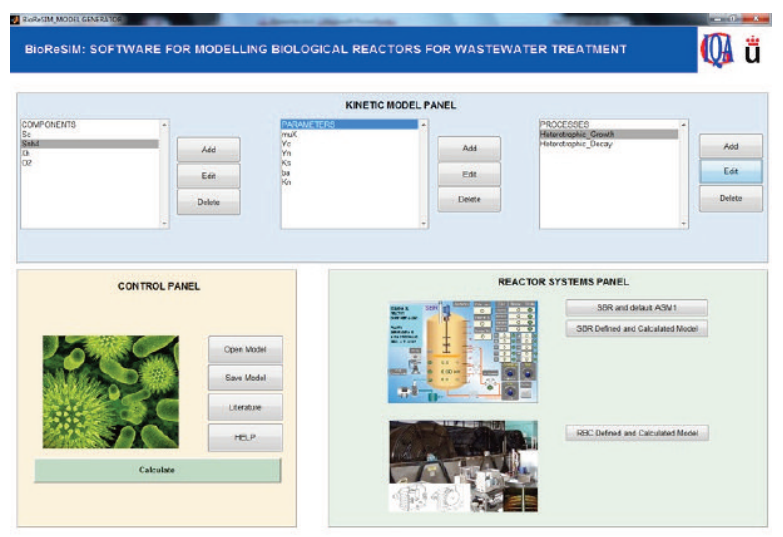

Figure 7. Example of a complete model after Calculation 


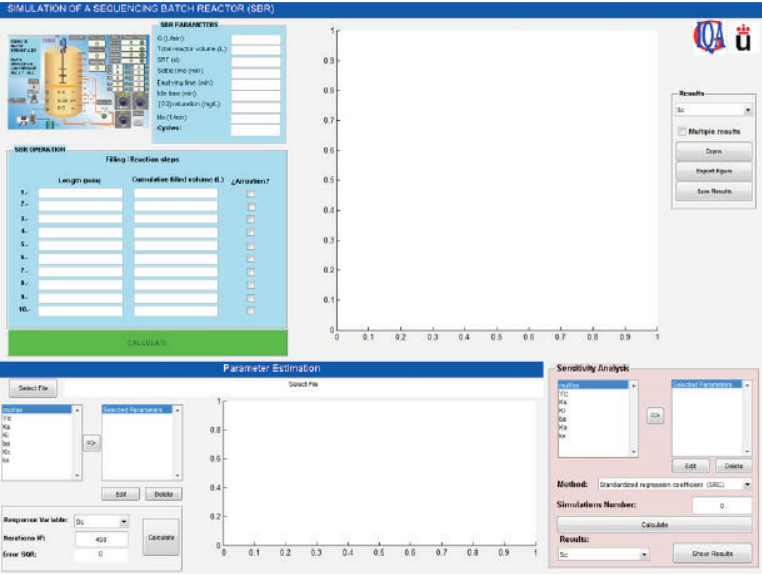

Figure 8. SBR simulator main screen

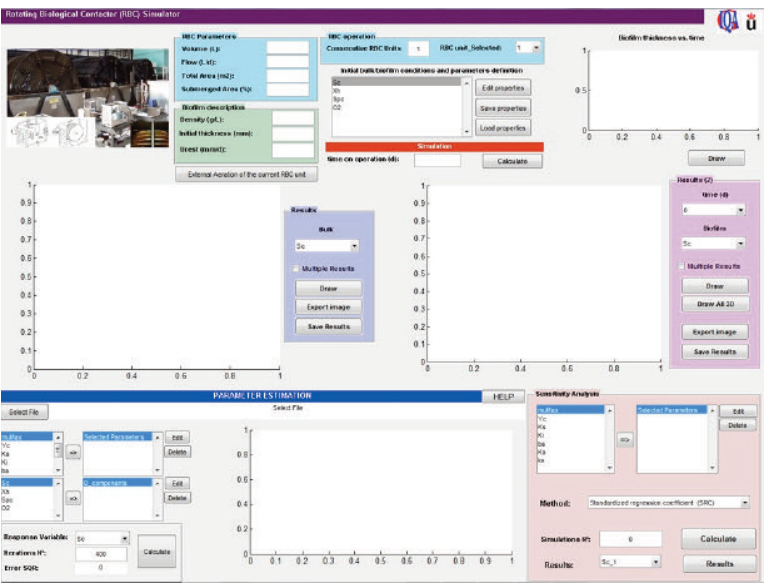

Figure 9. RBC simulator main screen

tions is the same that for the SBR Defined and Calculated Model, although the kinetic model (processes, components and parameters) is pre-fixed and only the SBR operating conditions, characterization of the influent and value of the parameters can be changed and studied.

\subsection{The SBR simulator screen}

Figure 8 shows the main screen of the SBR simulator which appears after SBR Defined and Calculated Model button is clicked. The upper half of the screen is devoted to the proper simulator of the SBR, whereas the lower half contains two panels for parameter estimation and sensitivity analysis of the parameters in the kinetic model. In the simulator, the main operating parameters of the SBR can be defined in the SBR PARAMETERS panel: total volume of the reactor, feed flow, time for settle, discharge and idle stages, sludge retention time $(S R T=\theta)$, saturation concentration of oxygen in water and oxygen mass transfer coefficient in water can be defined. Additionally, the number of complete cycles that the simulator will calculate can be also defined. After that, the fill and reaction steps can be defined by specification of time and total volume added to the reactor in the SBR OPERATION panel. Aeration can be also activated independently in each step. Finally, the Calculate button starts the calculation process.

For each stage, appropriate equation 1-8 will be solved, in which the term $r_{\mathrm{Ci}}$ and $r_{\mathrm{O}_{2}}$ will be taken according to the equations previously defined. All the calculated results along the time can be shown in the results section of the simulator (Figure 8, right hand of the screen). Additionally, the results can be saved with the Save Results button as ASCII and EXCEL format files, whereas the current figure can be export as *.jpg format using the Export figure button. The parameter estimation and sensitivity analysis panels are explained in the section 5.6 .

\subsection{The RBC simulator screen}

Figure 9 shows the main screen of the RBC simulator which appears after $R B C$ Defined and Calculated Model button is clicked. Following the scheme of the RBC simulator, the upper half of the screen is devoted to the RBC simulator, whereas the lower half contains two panels for parameter estimation and sensitivity analysis of the parameters defined previously in the kinetic model, similar to those described before for the SBR module.

In this case, more than one stage can be defined, being the influent for each additional stage the effluent from the previous one. Results, in terms of concentration of components in the bulk reactor with time and distribution of components in the biofilm thickness for all the stages are available from the calculation process. Finally, the evolution of the biofilm thickness for each stage can be also shown. All the data can be saved in ASCII and EXCEL format as in the SBR module. The parameter estimation and sensitivity analysis panels are explained in the section 5.6.

\subsection{Parameter Estimation and Sensitivity Analysis}

All the parameters defined in the kinetic model will be automatically available for parameter estimation in the SBR or RBC screen (Figure 8 and 9, lower left hand). The mathematical procedure follows the formulation of a nonlinear programming problem that minimizes the sum of quadratic residuals (SQR) between experimental measurements (upload from an excel file with the Select File button, Figures 8 and 9) and calculated model results. Although there are no restrictions of parameters for the estimation, this estimation is carried out considering only a response variable at the same time. The maximum and minimum value for each parameter can be defined, as well as the maximum number of iterations to obtain the results.

The sensitivity analysis allows the user to calculate linear sensitivity functions of variables with respect to each of the parameters included in the analysis, determining the uncertainty in any parameter according to the linear error propagation assumption. In BioReSIM, an adaptation of the Standardized Regression Coefficients (SRC) method is applied for the sensitivity studies. The SRC is a global sensitivity analysis method consisting in a multivariate linear regression between the model outputs (the compounds vs. time or position in the biofilm, in the case of the RBC system) and a distribution of values for one or more parameters of the model. This method considers linear models, in which for each parameter ( par $_{i}$ ) and for each model output $\left(y_{i}\right)$ of interest, the regression slope $\left(b_{i}\right)$ is standardized and the sensitivity coefficient $\left(\beta_{i}\right)$ is evaluated according to equation 19 (Saltelli et al. 2004; Reichter 1998; Mannina et al. 2012).

$$
\operatorname{SRC}\left(y, \mu_{i}\right)=\beta_{i}=\tilde{b}_{i} \frac{\sigma_{\mathrm{pat}}}{\sigma_{r}}
$$


In equation $19, \sigma_{p i}$ and $\sigma_{y}$ are the standard deviations of the values given to the parameters and the output results from the model, respectively. The $\beta_{i}$ value represents a measure of sensitivity for the input parameter par $_{i}$ in case that the linear regression coefficient $\mathrm{R}^{2}$ is greater than 0.7 (Saltelli et al. 2004). From this approach, other representative sensitiy parameters are calculated and shown in BioReSIM (Reichter 1998).

\section{Examples of aplication}

After presentation and description of BioReSIM, a couple of examples will be explained in order to have a first look to the capabilities of the simulator in teaching of wastewater treatment courses.

\subsection{Case of Study with the SBR}

This example is based on a recent experience (March 2014) developed in the Universidad Rey Juan Carlos with students belonging to the Degree in Food Science and Technology. A second semester subject, Food Technologies II is devoted to different technical aspects of food engineering such as wastewater treatments for food industry; a practical exercise with the SBR simulator was included as part of the lab-work.

\subsubsection{Case description}

Sequencing Batch Reactor is a suitable alternative for the treatment of milk industry wastewater because its ability to treat high organic loads and reducing nitrogen compounds by nitrification and denitrification (Sirianuntapiboon et al. 2005). A dairy milk factory produces pasteurized milk and UHT milk products, and the wastewaters are pretreated by coagulation and flocculation before degradation in a SBR. The reactor tank volume is $50 \mathrm{~L}$ and $25 \mathrm{~L}$ of clarified water is discharged in each operation cycle. The feed flow is $1 \mathrm{~L} / \mathrm{min}$, and the fill/reaction time is $250 \mathrm{~min}$., whereas settle, discharge and idle steps last $60 \mathrm{~min} ., 15 \mathrm{~min}$. and 15 min., respectively. The COD (named $\mathrm{S}_{\mathrm{C}}$ ) and nitrogen as $\mathrm{NH}_{4}^{+}$(named $\mathrm{S}_{\mathrm{nh}}$ ) of the inlet stream are 2600 $\mathrm{mg} / \mathrm{L}$ and $125 \mathrm{mg} / \mathrm{L}$, respectively. The presence of other dis- is shown in Table 4 (sufficient oxygen during the cycles has been assumed), whereas the calculated values for the parameters of the model are summarized in Table 5 .

According to the abovementioned data, the student will simulate the SBR process answering the following questions after analyzing the profiles of $\mathrm{S}_{\mathrm{c}}, \mathrm{S}_{\mathrm{nh} 4}$ and $\mathrm{X}_{\mathrm{h}}$ along a series of cycles:

a) To indicate the maximum carbon and nitrogen loadings in the SBR cycles and the time when these values are obtained.

b) To explain why the values of $\mathrm{S}_{\mathrm{C}}, \mathrm{S}_{\mathrm{nh}}$ and $\mathrm{X}_{\mathrm{h}}$ after the first cycle are not in concordance with the data show in the wording.

c) To define the proper concentrations in the SBR under steady-state conditions. How many cycles are necessary to achieve that operation conditions?

d) To explain what would happen if the concentration of $\mathrm{S}_{\mathrm{nh} 4}$ increases up to $200 \mathrm{mg} / \mathrm{L}$ in the feed flow.

e) If the temperature of the system suddenly drops to 10 ${ }^{\circ} \mathrm{C}$, changing the value of $\mu_{\mathrm{h}}$ from 4 to $2 \mathrm{~d}^{-1}$, how will the effluent composition be? How can the SBR be operated in order to minimize the $\mathrm{S}_{\mathrm{C}}$ and $\mathrm{S}_{\mathrm{nh}_{4}}$ in the effluent? Could you suggest a long-term solution for the operation of the reactor?

\subsubsection{Solving the case with BioReSIM}

The first step is introducing the kinetic model in the BioReSIM as it has been described previously. The components, parameters and processes defined in this example correspond to those shown previously in Figure 8. The resultant kinetic equations of the biochemical processes that would appear after clicking the calculation button are also shown. After running the case, the obtained results can be seen in Figure 10, and summarized as follows:

a) The maximum $\mathrm{S}_{\mathrm{C}}$ and $\mathrm{S}_{\mathrm{nh}}$ loading in the SBR occurs just at the end of the fill stage (25 minutes), with values of ca. 1600 and $50 \mathrm{mg} / \mathrm{L}$, respectively (Figure 10a).

\begin{tabular}{|c|c|c|c|c|}
\hline \multirow[t]{2}{*}{ Process } & \multicolumn{3}{|c|}{ Components of the system } & \multirow[t]{2}{*}{ Equation } \\
\hline & $\mathrm{S}_{\mathrm{C}}$ & $\mathrm{S}_{\mathrm{nh} 4}$ & $\mathrm{X}_{\mathrm{h}}$ & \\
\hline $\begin{array}{l}\text { Heterotrophic microbial growth } \\
\mathrm{S}_{\mathrm{C}}+\mathrm{S}_{\mathrm{nh} 4}+\mathrm{O}_{2}->\mathrm{X}_{\mathrm{h}}+\mathrm{CO}_{2}+\mathrm{H}_{2} \mathrm{O}\end{array}$ & $-1 / \mathrm{Y}_{\mathrm{C}}$ & $-1 / \mathrm{Y}_{\mathrm{N}}$ & 1 & $r_{1}=\mu_{h} \cdot\left(\frac{S_{C}}{K_{S}+S_{C}} \cdot \frac{S_{n h 4}}{K_{N}+S_{n h 4}}\right) \cdot X_{h}$ \\
\hline $\begin{array}{l}\text { Microbial decay } \\
\mathrm{X}_{\mathrm{h}}->\mathrm{X}_{\mathrm{h} \_ \text {dead (inert) }}\end{array}$ & o & o & -1 & $r_{2}=b_{h} \cdot X_{h}$ \\
\hline
\end{tabular}

Table 4. Proposed kinetic model for the biochemical processes

solved components was ruled out with the purporse of simplicity. The treated effluent showed a complete degradation of COD and $\mathrm{NH}_{4}^{+}$, whereas the concentration of volatile suspended solids (biomass, $\mathrm{X}_{\mathrm{h}}$ ) after a complete cycle was 5000 $\mathrm{mg} / \mathrm{L}$. An optimum sludge retention time of 20 days was considered. The fill and reaction processes were in presence of air, being the oxygen saturation concentration and mass transfer coefficient at $8 \mathrm{mg} / \mathrm{L}$ and $0.6 \mathrm{~min}^{-1}$, respectively. The model proposed for the different biochemical processes

\begin{tabular}{|l|c|l|c|}
\hline Parameter & Value & Parameter & Value \\
\hline$\mu_{\mathrm{h}}(1 / \mathrm{d})$ & 4 & $\mathrm{~K}_{\mathrm{N}}(\mathrm{mg} / \mathrm{L})$ & 1 \\
\hline $\mathrm{K}_{\mathrm{S}}(\mathrm{mg} / \mathrm{L})$ & 20 & $\mathrm{Y}_{\mathrm{N}}$ & 10 \\
\hline $\mathrm{Y}_{\mathrm{C}}$ & 0.48 & $\mathrm{~b}_{\mathrm{h}}(1 / \mathrm{d})$ & 0.8 \\
\hline
\end{tabular}




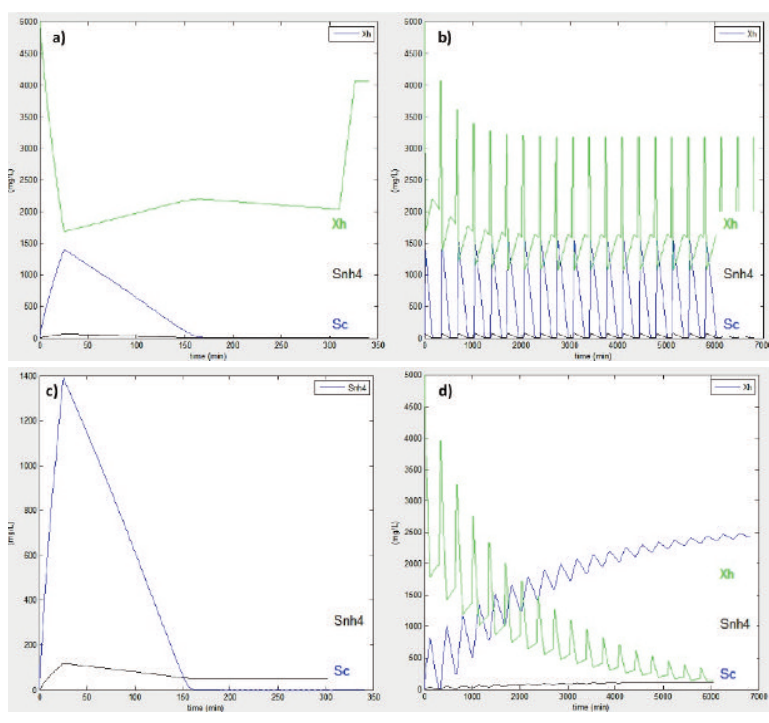

Figure 10. Details of the results obtained in the SBR simulator. Results panel without further mathematical treatment of the data.

These results correspond to the first cycle. Similar profiles but with different concentrations until reaching the steady-state could be seen for next cycles.

b) It is clearly evident that the biomass concentration $\mathrm{X}_{\mathrm{h}}$ falls from 5000 to $3800 \mathrm{mg} / \mathrm{L}$ during the first cycle, indicating non-steady operation conditions.

c) As can be seen in Figure 10b, steady-state conditions are achieved after 6 cycles, corresponding to $2010 \mathrm{~min}$. (33.5 hours in operation). In this case, a concentration of biomass of $3250 \mathrm{mg} / \mathrm{L}$ was reached in the SBR after a complete cycle.

d) If the $\mathrm{S}_{\mathrm{nh}} 4$ concentration in the feed flow increases, a remarkable $40 \mathrm{mg} / \mathrm{L}$ of it appears in the effluent from the $\mathrm{SBR}$, due to the $\mathrm{S}_{\mathrm{C}}$ is totally consumed before the $\mathrm{S}_{\mathrm{nh} 4}$.

e) In case of changing the temperature, a remarkable concentration of Sc in the effluent is obtained (Figure 10c). This can be solved by decreasing the feed flow to $0.2 \mathrm{~L} / \mathrm{min}$ (first cycle in Figure 10d). However, the SBR is not under steady-state, and further operation cycles produce a negative evolution in which the biomass is decaying with time and consequently the SBR loss activity. It is remarkable that in these conditions, a total loss of biomass from the reactor is obtained after $6000 \mathrm{~min}$ utes, corresponding to 18 operation cycles (4 days on operation).

\subsection{Case of Study with the RBC}

6.2.1. Case description

Alternatively to the SBR, the company has implemented a RBC system as complementary treatment. The RBC consists of a steel tank of $50 \mathrm{~L}$ with a package of disks of $4 \mathrm{~m}^{2}$ total area and $40 \%$ of their area will be submerged in the liquid. The feed flow is $100 \mathrm{~L} / \mathrm{d}$ and the attached biofilm can be characterized as heterotrophic consortium of $40000 \mathrm{mg} / \mathrm{L}$, being the density and the thickness of the wetted biofilm 50 $\mathrm{g} / \mathrm{L}$ and $0.5 \mathrm{~mm}$, respectively. The diffusion coefficient of each compound, the initial conditions of the reactor and the composition of the feed flow are shown in Table 6.

Assuming the attachment/detachment rate of biomass to the biodiscs is negligible under steady-state, non-active

\begin{tabular}{|l|c|c|c|c|}
\hline & $\mathbf{S}_{\mathbf{C}}$ & $\mathbf{S}_{\mathbf{N H}}$ & $\mathbf{X}_{\mathbf{h}}$ & $\mathbf{O}_{\mathbf{2}}$ \\
\hline $\boldsymbol{D}\left(\mathbf{d m}^{2} / \mathbf{d}\right)$ & 0.018 & 0.015 & 0 & 0.1 \\
\hline $\begin{array}{l}\text { Initial concentration } \\
\text { of the components in } \\
\text { the bulk reactor } \\
\text { (mg/L) }\end{array}$ & 2600 & 125 & 0 & 8 \\
\hline $\begin{array}{l}\text { Initial concentration } \\
\text { of the components in } \\
\text { the biofilm (mg/L) }\end{array}$ & 0 & 0 & $\begin{array}{c}4000 \\
0\end{array}$ & 8 \\
\hline $\begin{array}{l}\text { Concentration of com- } \\
\text { ponents in the feed } \\
\text { flow (mg/L) }\end{array}$ & 2600 & 125 & 0 & 8 \\
\hline
\end{tabular}

Table 6. Parameters of the RBC system

biomass in the bulk reactor, non-significant effect of external aeration $\left(f_{A E R A T I O N}=O\right)$ and the same kinetic model than that shown in Tables 4 and 5, the students will run the simulation and analyze the following points:

a) Profiles of the $\mathrm{S}_{\mathrm{C}}, \mathrm{S}_{\mathrm{nh}}$ concentration in the effluent and biofilm thickness during 20 days of operation.

b) Evolution of the biofilm thickness.

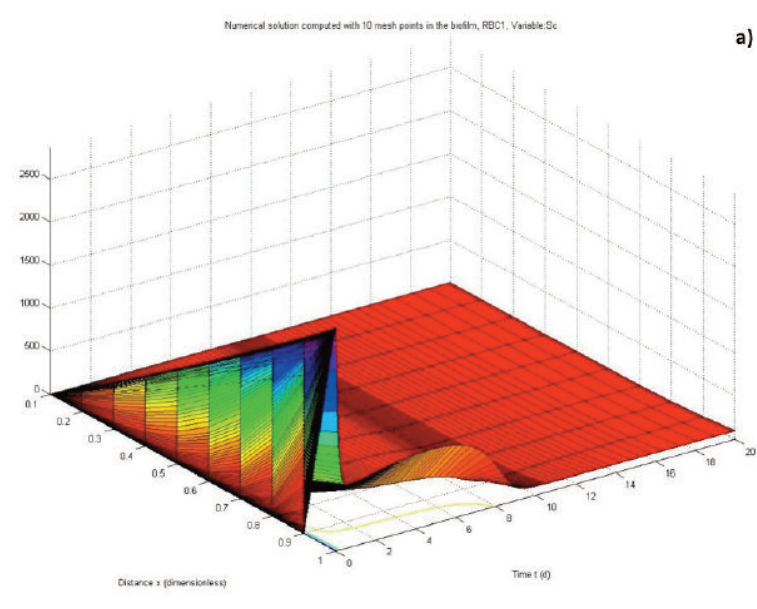

b)

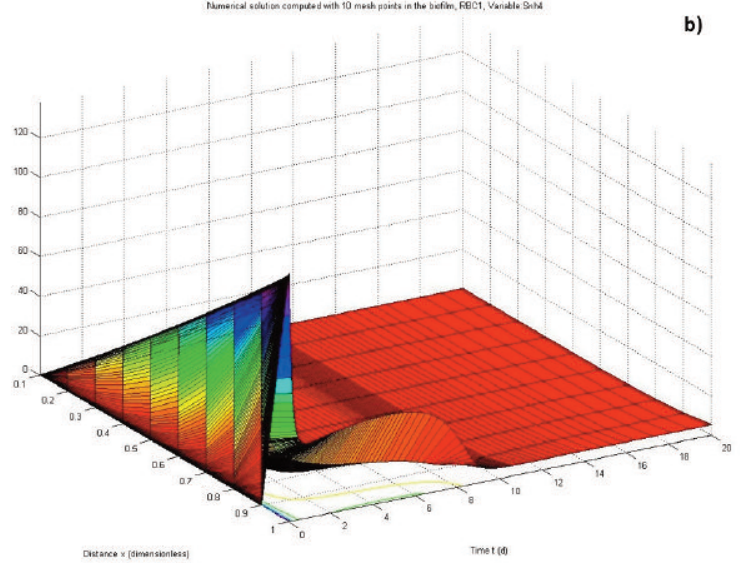

Figure 11. Profiles of a) $S_{C}$ and b) $S_{n h 4}$ in the biofilm (Distance $x<1$ ) and in the bulk solution $(x=1)$ with time. 


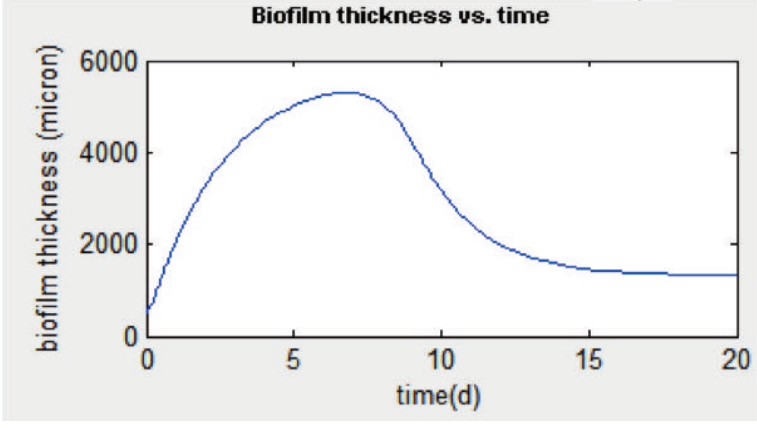

Figure 12. Evolution of biofilm thickness with the operation time.

\subsubsection{Solving the case with BioReSIM}

The kinetic model is exactly the same than that used in example 6.1 and shown in Figure 8. The profiles of $\mathrm{S}_{\mathrm{C}}$ and $\mathrm{S}_{\mathrm{nh} 4}$ along time in the biofilm thickness are shown in Figure 11. Additionally, the concentration of dissolved components in the bulk solution can be taken from the concentration in the biofilm in contact with the reaction media (distance $\mathrm{x}=1$ in the figures) according to the boundary condition of equation 17. After 10 days, $\mathrm{S}_{\mathrm{C}}$ and $\mathrm{S}_{\mathrm{nh}_{4}}$ in the effluent were 95 and $6 \mathrm{mg} / \mathrm{L}$, respectively. Regarding the biofilm thickness, steady $2 \mathrm{~mm}$ thickness was obtained after ca. 10 days, as can be seen in Figure 12. Although more information can be obtained from the results, these Figures 11 and 12 are a good example of the basic capacities of the BioReSIM for the simulation of RBC systems.

\section{Conclusions}

BioReSIM allows the evaluation of simple and complex kinetic biological models, as well as operational conditions of two different bioreactors (sequencing batch reactor and rotating biological contactors) through a friendly and graphic user interface, avoiding the development of complex codes. This BioReSIM application proposes an easy way to study the influence of different biochemical processes on the bioreactor performance, by definition user-made kinetic equations. Additionally, the application can be used not only as a biological reactor simulator but also for parameter estimation and sensitivity analysis calculations, being a complete tool not only for researcher but also for teaching and learning applications in the field of biological reactors for wastewater treatment.

\section{Literature}

Lant, Paul, Emmett, David. "Using the World Wide Web to revolutionise technology transfer and training in the water and wastewater industries". Water Science and Technology, 44(2-3), (2001): 127-134.

Morgenroth, Eberhard, Arvin, Erik, Vanrolleghem, Peter A. "The use of mathematical models in teaching wastewater treatment engineering". Water Science and Technology, 45(6), (2002): 229-233.

Henze, Mogens, Grady, C. P. Leslie, Gujer, Willi, Marais, Gerrit v., and Matsuo, Tomonori. "Activated sludge model no. 1" Scientific and Technical Report 1, IAWPRC Task Group on Mathematical Modelling for Design and Operation of Biological Wastewater Treatment Processes, IAWPRC, London, 1986.

Henze, Mogens, Gujer, Willis, Mino, Takashi and van Loosdrecht, Mark. "Activated Sludge Models ASM1, ASM2, ASM2d, and ASM3". IWA Task Group on Mathematical Modelling for Design and Operation of Biological Wastewater Treatment, 2000.

Poltack, Ronald F. "Sequencing Batch Reactor Design and Operational Considerations". New England Interstate Water Pollution Control Commission. The Environmental Outreach Group New England and New York Regional 104(g) Workgroup, 2005.

Fernández, Isaac, Suárez-Ojeda, María Eugenia, Pérez, Julio, Carrera, Julián. “Aerobic biodegradation of a mixture of monosubstituted phenols in a sequencing batch reactor", Journal of Hazardous Materials, 260(15) 2013: 563-568.

http://dx.doi.org/10.1016/j.jhazmat.2013.05.052

Pathwardan, Ashwin W. "Rotating biological contactors: a review”, Industrial and Engineering Chemistry Research, 42, 2003: 2035-2051. http://dx.doi.org/10.1021/ieo200104

Pariente, María Isabel, Siles, Jose Ángel, Molina, Raúl, Botas, Juan Ángel, Melero, Juan Antonio, Martínez Fernando. "Treatment of an agrochemical wastewater by integration of heterogeneous catalytic wet hydrogen peroxide oxidation and rotating biological contactors", Chemical Engineering Journal, 226, 2013: 409-415. http://dx.doi.org/10.1016/j.cej.2013.04.081

Saltelli, Andrea, Tarantola, Stefano, Campolongo, Francesca and Ratto, Marco. "Sensitivity analysis in practice. A guide to assessing scientific models". Probability and Statistics Series. John Wiley \& Sons, Chichester, UK, 2004.

von Schulthess, Reto, Gujer Willi. "Release of nitrous oxide ( $\left.\mathrm{N}_{2} \mathrm{O}\right)$ from denitrifying activated sludge: Verification and application of a mathematical model", Water Research, 30(3), 1996: 521-530. http://dx.doi.org/10.1016/0043-1354(95)oo204-9

Reichter Peter. "AQUASIM 2.o. User Manual”. Swiss Federal Institute of Environmental Science and Technology (EAWAG), Duebendorf, Switzerland, 1998.

Mannina, Giorgo, Cosenza, Alida, Viviani, Gaspare, Vanrolleghem, Peter A., Neumann, Marc B. "Global sensitivity analysis for urban water quality modelling: comparison of different methods". 9th International Conference on Urban Drainage Modelling Belgrade, 2012.

Sirianuntapiboon, Suntud, Jeeyachok, Narumond, Larplai, Rarintorn. "Sequencing batch reactor biofilm system for treatment of milk industry wastewater". Journal of Environmental Management, 76(2), 2005: 177-183. ttp://dx.doi.org/10.1016/j.jenvman.2005.01.018 